Check for updates

Cite this: RSC Adv., 2019, 9, 24659

Received 31st May 2019

Accepted 3rd August 2019

DOI: 10.1039/c9ra04123k

rsc.li/rsc-advances

\section{Preparation of hydrophobically modified cotton filter fabric with high hydrophobic stability using ARGET-ATRP mechanism}

\author{
Zheng Li, (DD ab Zijian He, ${ }^{\text {ab }}$ Xiaodan Chen, (D) ${ }^{\mathrm{c}}$ Yi Tang, ${ }^{\mathrm{e}}$ Shiwen You, ${ }^{\mathrm{e}}$ Yufang Chen ${ }^{\star a c d}$ \\ and Tao Jin ${ }^{\star a c d}$
}

This paper reports on the hydrophobic modification of cotton fabric grafted with 1-octadecene via an activators regenerated by electron transfer (ARGET) atom transfer radical polymerization (ATRP) mechanism. Particularly, the activation treatment of raw cotton fabric, its influence on the graftcopolymerization by the ARGET-ATRP method, along with the super-hydrophobicity and hydrophobic stability of the modified cotton fabric are discussed. Furthermore, the microstructure and elemental variation were characterized by scanning electron microscopy (SEM), atomic force microscopy (AFM), X-ray photoelectron spectroscopy (XPS), and the energy dispersion spectrum (EDS) technique. The results show that chemical activation of the raw cotton fabric can significantly improve the follow-up hydrophobic modification process. Specifically, the contact angle of the hydrophobically modified cotton fabric increased to $145^{\circ}$ after activation, and thus, this fabric presents more stable hydrophobicity (corresponding to a $5.5 \%$ contact angle attenuation) than a non-activated fabric. The hydrophobic modification reaction was carried out using a chemically optimum stoichiometric ratio of $m\left(\mathrm{CuBr}_{2}\right): m\left(\mathrm{C}_{9} \mathrm{H}_{23} \mathrm{~N}_{3}\right): m\left(\mathrm{C}_{2} \mathrm{H}_{5} \mathrm{OH}\right): m\left(\mathrm{C}_{18} \mathrm{H}_{36}\right): m\left(\mathrm{C}_{6} \mathrm{H}_{8} \mathrm{O}_{6}\right)=$ $0.015: 0.052: 17.9: 2.4: 0.05$, at a temperature of $30-55{ }^{\circ} \mathrm{C}$ over $8 \mathrm{~h}$. Furthermore, the SEM and AFM images revealed that more copolymer micro/nano-level particles were present on the surface of the fibers of the hydrophobically modified cotton fabric, indicating that the hydrophobic property and stability of the cotton fabric increase with the grafting density on the cotton fabric.

\section{Introduction}

Filtration techniques are used to efficiently separate materials in processes like liquid separation, purification, and cleanup, ${ }^{1-3}$ with the key element in the filtering process being the filtration material. These include synthetic fibers, ${ }^{4}$ cotton-fiber fabrics, ${ }^{5}$ and metal meshes. ${ }^{6}$ In particular, cotton fabric is a very important and valuable separation material given its advantages of being renewable, highly abundant, and ecofriendly, ${ }^{7,8}$ all of which differentiate it from other filtration materials.

Nevertheless, cotton fabric is normally used only for primary filtration rather than precision and higher-efficiency separation, even if it has a large filtration flux. However, the functional modification process has proven to be an effective means to

\footnotetext{
${ }^{a}$ Guangzhou Institute of Chemistry, Chinese Academy of Sciences, Guangzhou 510650, China.E-mail:yfchen@gic.ac.cn; jintao@gic.ac.cn

${ }^{b}$ University of Chinese Academy of Sciences, Beijing 10049, China

'Guangzhou CAS Test Technical Services Co., Ltd, Guangzhou 510650, China

${ }^{d}$ Chinese Academy of Sciences Guangzhou Chemical Co., Ltd., Guangzhou 510650, China

${ }^{e}$ Chongqing CAS Test Technical Services Co., Ltd, Chongqing 400700, China
}

improve the functionality of cotton fabric. For example, it can be endowed with properties such as anti-fouling, ${ }^{9,10}$ anticlogging, anti-corrosion, ${ }^{11}$ and highly efficient and precise separation. ${ }^{12}$ Furthermore, super-hydrophobic cotton fabric has been developed for several applications such as oil-water separation in waste-water treatment.

Wu et al. ${ }^{13}$ prepared a superhydrophobic cotton fabric (SCF) via the radiation-induced graft polymerization of lauryl methacrylate (LMA) and $n$-hexyl methacrylate (HMA), which can be prompted to self-heal by ironing. Qing et al. ${ }^{14}$ coated thin cotton fabric with $\mathrm{ZnO} /$ polystyrene to obtain a superhydrophobic material that was very well suited to oil-water separation applications. Cao et al. ${ }^{15}$ deposited an organic modified silica aerogel film on a fabric and then coated it with polydimethylsiloxane (PDMS) to produce a composite super-wetresistant fabric with excellent antifouling and self-cleaning properties while offering excellent oil-water separation performance.

These works focused on different physical means of preparing functionally modified cellulose fabric with excellent amphiphobic performance and properties that were tailored for application to commercial oil-water separation processes. ${ }^{\mathbf{1 3 - 1 6}}$ However, the hydrophobic stability and durability of 
functionally modified cellulose fabrics prepared by this physical method have often been neglected in such studies. Thus, overcoming the rapid loss of functionally modified cellulose fabric surface coatings in practical applications is a challenge.

The chemical modification of cellulose filter fabric should be addressed as a means of developing new functional materials. In this case, "chemical modification" refers not only to the structural and functional reconstruction of the cellulose filter fabric but also to the way in which the amphiphobic durability and reliability can be improved when applied to a separation process. ${ }^{17,18}$

A typical study was undertaken by Carlmark, ${ }^{19}$ in which the graft-copolymerization of methyl acrylate (MA) with cellulose was performed to attain the hydrophobic functional modification of cellulosic materials when combined with the atom transfer radical polymerization (ATRP) method..$^{20,21}$ Since then, improved methods for the graft-copolymerization of cellulose and cellulosic derivatives have been reported, such as SIATRP $^{22-24}$ and ARGET-ATRP. ${ }^{25,26}$ Similarly, progress has been made in the functional graft-copolymerization of methyl methacrylate (MMA), styrene (St), and glycidyl methacrylate (GMA) on filter paper. Moreover, a cotton-graft-poly $(N, N$-dimethylaminoethyl methacrylate) (PDMAEMA) reaction was successfully carried out, creating a low-adhesion hydrogel wound dressing using the SI-ARGET-ATRP method. ${ }^{27}$ All these studies have widened the applied range of the ATRP reaction system and expanded the application field of cellulosic functional materials.

In general, studies of the functional modification of cellulose using the ARGET-ATRP method have attracted considerable interest and have garnered more attention as progress has been made with modification reactions, as well as the amphiphobic property and adaptability of functionally modified cellulose.

In the present study, an activation process ${ }^{28,29}$ was applied to improve the cellulose reactivity during the graft copolymerization with 1-octadecene as part of the ATRP process. Furthermore, the hydrophobicity and hydrophobic stability characteristics of modified cotton fabric were explored with the goal of developing a reaction that is well matched to the hydrophobic modification of cotton fabric by the ARGET-ATRP method.

\section{Experimental}

\subsection{Materials}

Sodium hydroxide, urea, ethanol, acetone, and triethylamine (TEA), were acquired from Guangzhou Chemical Reagent Factory. Copper bromide (CB), pentamethyldiethylenetriamine (PMDETA), $\alpha$-bromoisobutyryl bromide (BiB), dimethylaminopyridine (DMAP), ascorbic acid (Vc), dichloromethane (DCM), and 1-octadecene (1-Oct) were purchased from Aladdin Reagent (Shanghai) Co., Ltd. The activating agent (AA) used to activate the cellulosic fabric was a mixture of sodium hydroxide and urea, combined at a ratio of $m(\mathrm{NaOH}): m\left(\left(\mathrm{NH}_{2}\right)_{2} \mathrm{CO}\right)=3: 2$. We made this AA ourselves in the laboratory. The cotton fabric, made of unbleached $100 \%$ cotton fiber, commonly used as a filter material for solid-liquid separation, was purchased from a commercial supplier.

\subsection{Reaction mechanism and synthetic route diagram}

During the course of ARGET-ATRP, inactive $\mathrm{Cu}(\mathrm{II})$ ions are continuously reduced to active $\mathrm{Cu}(\mathrm{I})$ ions by a reducing agent, while a continuous copolymerization reaction between the monomer and the cellulose ${ }^{25,30}$ occurs, (Fig. 1). Moreover, the reaction conditions of the ARGET-ATRP process are milder and simpler ${ }^{\mathbf{1 9 , 2 0}}$ than those of the basic ATRP method.

The cotton fabric (or activation cotton fabric) reacts with $\mathrm{BiB}$ and then undergoes graft copolymerization with 1-octadecene by the ARGET-ATRP process to hydrophobically modify the cotton fabric (Fig. 2).

\subsection{Activation of cleaned cotton fabric}

A cotton fabric sample measuring $2 \times 4 \mathrm{~cm}$ was washed ultrasonically in a mixture of water, acetone, and ethanol for $5 \mathrm{~min}$ at room temperature, then dried in a vacuum drier. The resulting cleaned cotton fabric was immersed in an AA-ethanol solution for $2 \mathrm{~h}$ at room temperature, then rinsed to neutrality with ethanol, and finally dried at $100{ }^{\circ} \mathrm{C}$ in a vacuum drier to produce the activated cotton fabric.

\subsection{Preparation of esterified cotton fabric}

The cotton fabric (activated cotton fabric), along with $50 \mathrm{ml}$ of DCM, $0.6 \mathrm{~g}$ of DMAP, $2.5 \mathrm{ml}$ of TEA, and BiB were added, in the stated order, to a three-necked flask at $5{ }^{\circ} \mathrm{C}$, which was equipped with a stirred reflux condenser and nitrogen protection. The stirring was continued for $1 \mathrm{~h}$, while the reaction temperature was raised to $30{ }^{\circ} \mathrm{C}$ and then held at that temperature for the set reaction time. Finally, esterification cotton fabric (ECF) (esterification activation cotton fabric (EACF)) was obtained after separating, cleaning, and drying in a vacuum oven at $100{ }^{\circ} \mathrm{C}$.

\subsection{Graft-copolymerization of esterification cotton fabric by ARGET-ATRP}

The ECF (EACF) obtained from the above process, $15 \mathrm{mg}$ of $\mathrm{CuBr}_{2}, 52 \mathrm{mg}$ of PMEDTA, $17.9 \mathrm{~g}$ of ethanol, and 1-octadecene were added, in the stated order, to a three-necked flask while being stirred to circulate the reflux under a nitrogen atmosphere. Then, a Vc-ethanol solution $\left(10 \mathrm{mg} \mathrm{ml}^{-1}\right)$ was added

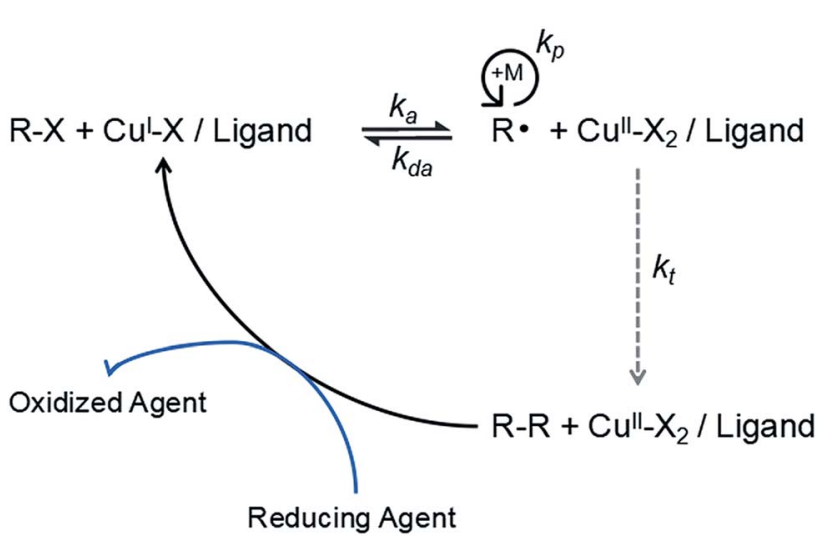

Fig. 1 ARGET-ATRP mechanism. 
Raw cotton fabric Activation cotton fabric Esterification cotton fabric Hydrophobic modified cotton fabric

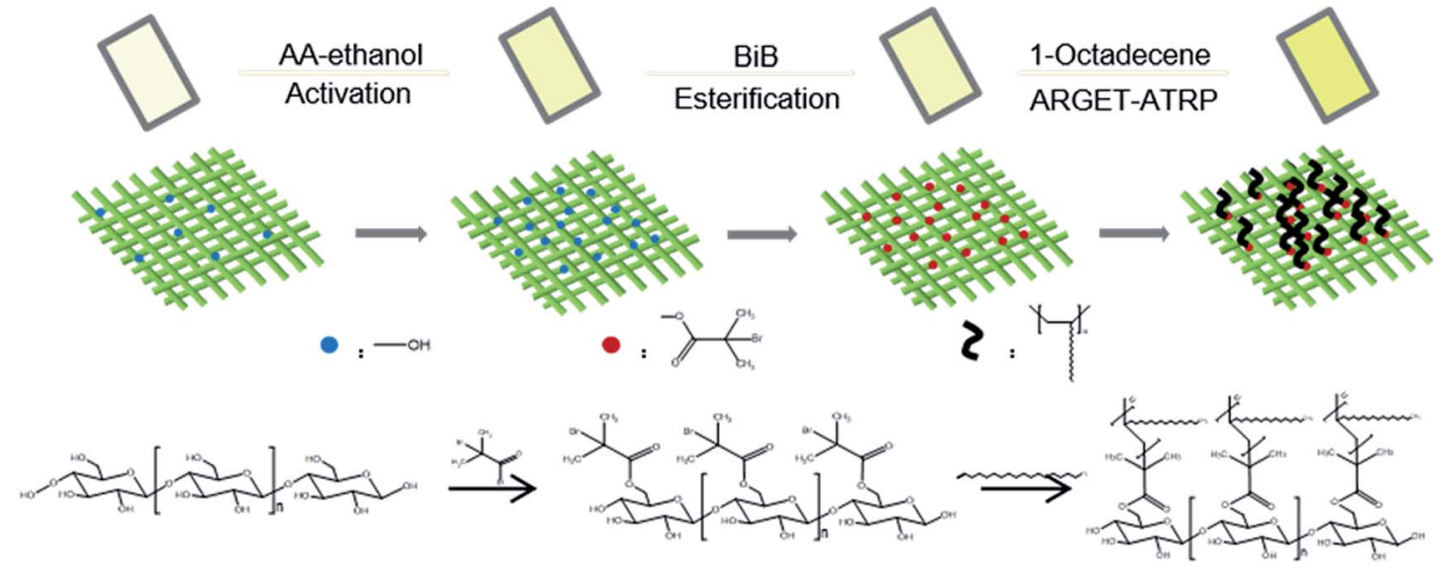

Fig. 2 Schematic of preparation of hydrophobically modified cotton fabric.

dropwise to the reaction mixture, while the reaction was allowed to continue for a set time at a constant temperature. A hydrophobically modified cotton fabric (HMCF) was produced after separation, ultrasonic cleaning in an acetone-ethanol mixture, Soxhlet extraction, and then vacuum drying.

\subsection{Measurement of contact angle of cotton fabric}

The contact angle of $5 \mu \mathrm{l}$ water droplets on the cotton fabric surface was measured using a contact angle measuring instrument (error of $\pm 0.5^{\circ}$ ) (JC2000C, Zhongchen, China). The contact angle was taken as the mathematical mean of ten different contact angles acquired from ten points on the HMCF sample at room temperature.

Meanwhile, the variation in the contact angle over time can be described by two parameters. The first factor is called the contact angle (CA), which corresponds to the starting and original contact angle value, named $V_{\mathrm{CA}}$, while the other is the residual contact angle (RCA) of the starting CA after a $10 \mathrm{~min}$ natural self-attenuation, that is, the real-time contact angle, $V_{\text {RCA }}$.

Furthermore, the corresponding contact angle decay rate $\left(D_{\mathrm{r}}\right)$ is calculated based on $V_{\mathrm{CA}}$ and $V_{\mathrm{RCA}}$ :

$$
D_{\mathrm{r}}=\left[\left(V_{\mathrm{CA}}-V_{\mathrm{RCA}}\right) /\left(V_{\mathrm{CA}}\right)\right] \times 100 \%
$$

where $D_{\mathrm{r}}$ is the contact angle stability or hydrophobic stability of the HMCF. A smaller $D_{\mathrm{r}}$ value corresponds to a more stable hydrophobicity of HMCF.

\subsection{Characterization}

The distribution of chemical elements on the surface of the cotton fabric was determined by energy dispersion spectroscopy (EDS, X-Max, Oxford Instruments Inca). Further, X-ray photoelectron spectroscopy (XPS, $\mathrm{Xi}^{+}$, Esca Lab) was used to confirm the chemical element information on the cotton fabric. The excitation source was $\mathrm{Al} \mathrm{K} \alpha \mathrm{X}$-rays, and the take-off angle was $90^{\circ}$. The two-dimensional morphology and structure of the surface fibers of the cotton fabric were observed at $2.0 \mathrm{kV}$ using scanning electron microscope (SEM, SU-70, Hitachi). Atomic force microscopy (AFM, Multimode 8, Bruker) was used to acquire the three-dimensional shape and structural information of the fibers on the surface of the cotton fabric.

\section{Results and discussion}

\subsection{Effect of activation on graft-copolymerization of cotton fabric by ARGET-ATRP}

A cellulosic graft-copolymerization is generally assumed to react with the alcoholic hydroxyl group of the glucose units, ${ }^{28,29}$ but given the chemical inertness of the former, this reaction is difficult to instigate. Therefore, in the present study, a chemical activation process was adopted to activate and improve the reactivity of the cotton fabric over the course of the graftcopolymerization reaction with ARGET-ATRP.

To investigate the effect of the AA concentration on the CA of $\mathrm{HMCF}$, a reaction between an overdose of $\mathrm{BiB}$ and cotton fabric with different activation degrees was first performed at $30{ }^{\circ} \mathrm{C}$ for $24 \mathrm{~h}$ to obtain ECF/EACF, and then the ECF/EACF was introduced to the graft-polymerization with 1-octadecene to produce HMCF.

The influence of HMCF on CA before and after the activation process is shown in Fig. 3 a by a contrastive analysis. The results show that the $V_{\mathrm{CA}}$ and $V_{\mathrm{RCA}}$ values of $\mathrm{HMCF}$ vary with an increase in the AA dosage, with one peak appearing at an AA dosage of $2.8 \%$. The peak $V_{\mathrm{CA}}$ of HMCF with the activation treatment was found to be $137.5^{\circ}$, which is higher than that of the control sample $\left(126^{\circ}\right)$, which had not been subjected to the activation treatment.

The lowest $D_{\mathrm{r}}$ value was found to be $6.2 \%$ at the peak $V_{\mathrm{CA}}$ corresponding to the $3 \mathrm{wt} \%$ AA dosage. The $D_{\mathrm{r}}$ value was found to increase with the distance from the peak position. This suggests that the application of a suitable activation process to the cotton fabric can improve the hydrophobic stability of HMCF, as shown in Fig. 3 (curve $a_{2}$ ). 

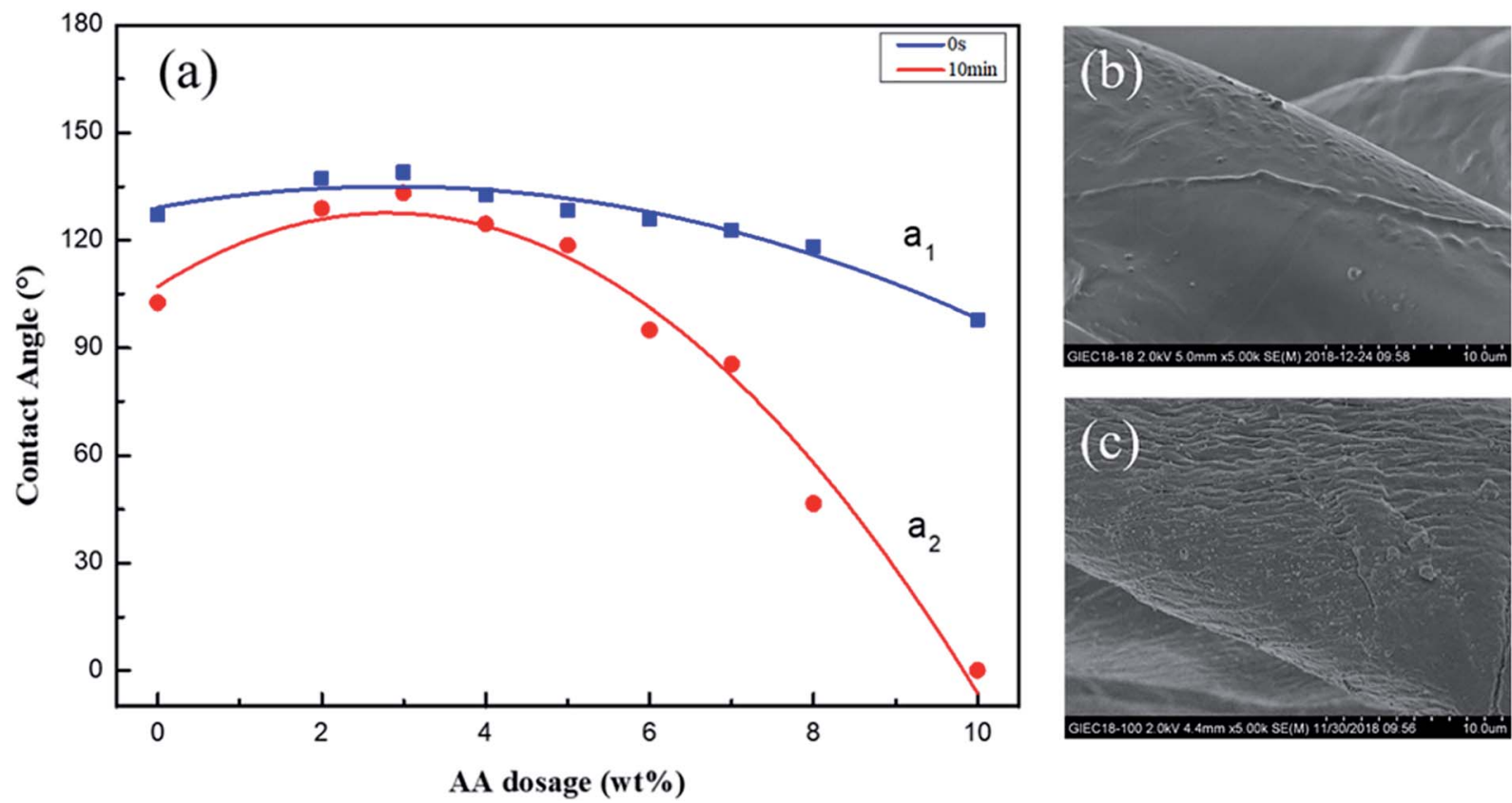

Fig. 3 (a) Changes in $V_{C A}$ and $V_{\text {RCA }}$ with variation in AA dosage, (b) SEM images of HMCF not subjected to activation and, (c) subjected to activation.

Fig. $3 \mathrm{~b}$ and c compares the morphology of the HMCF before and after the activation process. The HMCF fiber surface with activation has a rough, wrinkled, and multi-granular surface structure (Fig. 3c), in contrast to the non-activated one, which is relatively smooth, faintly wrinkled, and has only a slight graininess (Fig. 3b). This is caused by the sodium hydroxide in the AA being incorporated into the superficial layer of the cotton fibers, thus affecting the hydroxyl groups of the cellulose, and weakening the hydrogen bond between the cellulose macromolecules or in the molecule. This results in more alcoholic hydroxyl groups of cellulose being released, increasing the number of hydroxyl groups contributing to the esterification reaction. Meanwhile, the lower-level activation of the cellulose is not conducive to obtaining a sufficient number of active hydroxyl groups. In contrast, when an excessive amount of cellulose is added, the number of active hydroxyl groups may increase the risk of the cellulose macromolecular chains breaking. Excessive breakage of the macromolecular chains can expose more polar hydroxyl groups, which would be detrimental to the hydrophobicity of the cellulose in the case of a low-level esterification reaction.

\subsection{Parameters affecting esterification reaction and the effect on the hydrophobic properties of cotton fabric}

The influence of the esterification reaction control parameters on HMCF improves the esterification reaction and the ARGETATRP process for cotton fabric.

The optimally activated cotton fabric was reacted with $\mathrm{BiB}$ for $24 \mathrm{~h}$ to obtain an EACF, then further reacted with 1-octadecene by ARGET-ATRP to produce an HMCF. Fig. 4a shows that the $V_{\mathrm{CA}}$ and $V_{\mathrm{RCA}}$ of the HMCF appear to rapidly increase in the initial period prior to the $0.5 \mathrm{ml} \mathrm{BiB}$ dosage, and then increase smoothly and steadily as the BiB dosage is increased. The variation in $D_{\mathrm{r}}$ rapidly decreases to attain a steady-state value of $6.7 \%$. For a certain degree of activation of the cotton fabric, a smaller amount of $\mathrm{BiB}$, accompanied by a lower degree of esterification reaction, leads to the weakening of the graftedcopolymerization process by the ARGET-ATRP method, which is disadvantageous to the hydrophobicity of the HMCF. As the amount of $\mathrm{BiB}$ is increased to $0.5 \mathrm{ml}$, the reaction with the activated hydroxyl groups of the cotton fabric may gradually reach completion, such that any further increase in the BiB dosage will not result in an improvement of the graftcopolymerization by the ARGET-ATRP method. Finally, the CA and RCA of the HMCF tend to be stable.

In Fig. $4 \mathrm{~b}$, the $V_{\mathrm{CA}}$ and $V_{\mathrm{RCA}}$ of the HMCF increase rapidly in the first $4 \mathrm{~h}$, and subsequently stabilize, as $D_{\mathrm{r}}$ stabilizes at $6.3 \%$ over time and the progress of the esterification reaction. The reaction time affects the modified reaction of the HMCF in a similar way to increasing the dosage of $\mathrm{BiB}$, with a certain quantity of the activated hydroxyl groups completely reacting with the BiB within $4 \mathrm{~h}$. As such, any extension of the reaction time will not affect either the degree of esterification or the grafted-copolymerization of HMCF. Thus, the $V_{\mathrm{CA}}$ and $V_{\mathrm{RCA}}$ of the HMCF tend to be stable, with the hydrophobic stability exhibiting the optimal state.

\subsection{Characteristics of EACF}

An efficient esterification reaction ${ }^{21}$ between the cotton fabric and $\mathrm{BiB}$ is the basis of the subsequent hydrophobic modification reaction in an ARGET-ATRP process. To better understand the changes in the cotton fabric during the esterification 

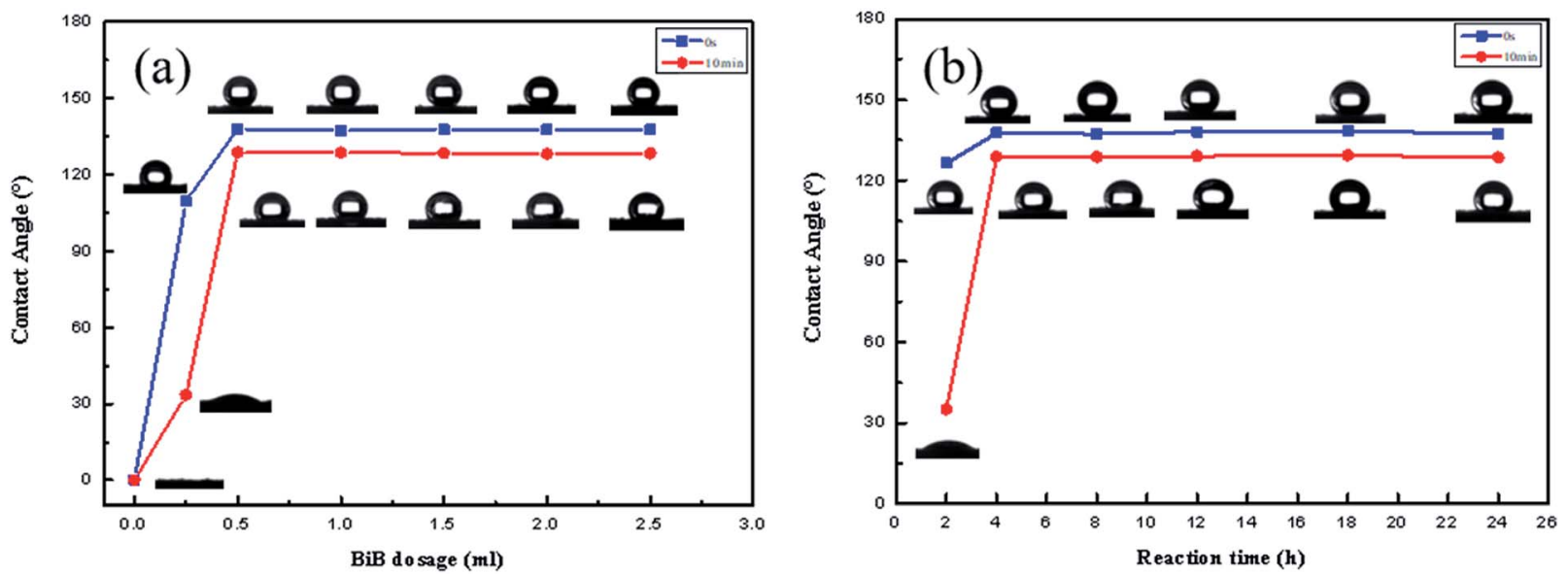

Fig. 4 CA and RCA of HMCF with variations in (a) the BiB dosage and (b) the reaction time.

reaction, a comparative XPS analysis of the surface characteristics of HMCF before and after activation was carried out, as shown in Fig. 5a and b with the corresponding C1s separation peak spectrum shown in Fig. $5 \mathrm{c}$ and d.
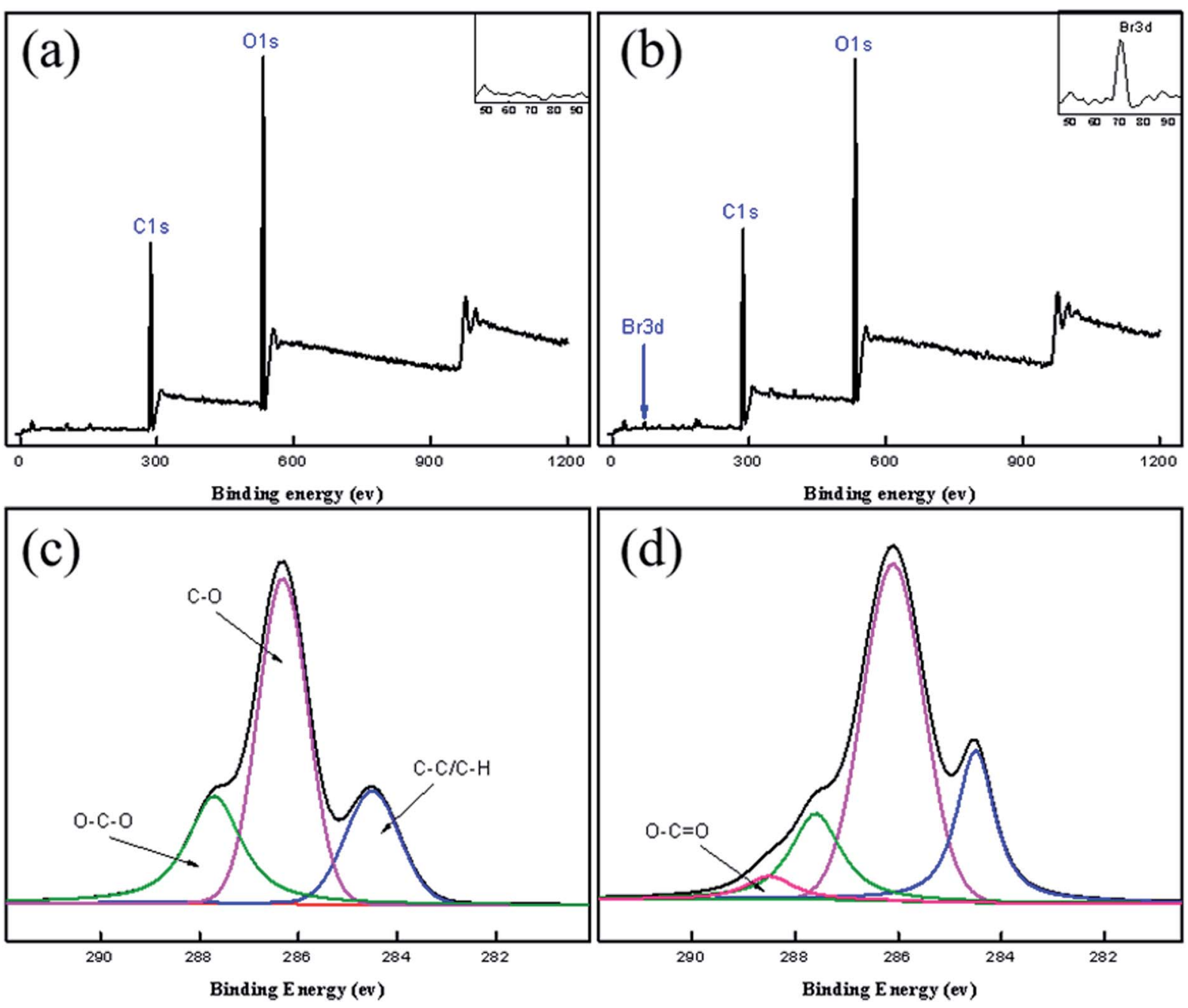

Fig. 5 XPS wide-scan spectra for (a) raw cotton fabric and (b) EACF. C1s peak map of (c) raw cotton fabric and (d) EACF. 
In Fig. 5a, not only are the signal peaks of C1s $(284.6 \mathrm{eV})$ and O1s $(527.9 \mathrm{eV})$ of the cleaned original cotton fabric visible, but there is also an extra, weak Br3d peak of the esterified cotton fabric at $70 \mathrm{eV}$ (Fig. 5b), which is consistent with the features described by Carlmark. ${ }^{29}$ In Fig. $5 \mathrm{c}$ and d, the C1s peak (284.6 $\mathrm{eV}$ ) of the cleaned raw cotton fabric can be divided into $\mathrm{C}-\mathrm{C} / \mathrm{C}-$ $\mathrm{H}(284.6 \mathrm{eV}), \mathrm{C}-\mathrm{O}(286.2 \mathrm{eV})$, and $\mathrm{O}-\mathrm{C}-\mathrm{O}(287.7 \mathrm{eV})$ fragments, with an additional weak EACF signal peak appearing near $288.7 \mathrm{eV}$, which belongs to the $\mathrm{O}=\mathrm{C}-\mathrm{O}$ fragment. Furthermore, the morphology of the EACF was characterized by SEM and EDS (see Fig. 6). The carbon, oxygen, and bromine elements can be observed in Fig. 6b-d, with their distributions being even over a $50 \mu \mathrm{m}$ scale. This provides conclusive evidence for the esterification reaction between the cotton fabric and BiB.

In summary, the optimized and desired esterification process of the activated cotton fabric could be performed with $0.5 \mathrm{ml}$ of $\mathrm{BiB}$ at $30^{\circ} \mathrm{C}$ over $4 \mathrm{~h}$, with the corresponding $V_{\mathrm{CA}}$ and $V_{\mathrm{RCA}}$ values of the $\mathrm{HMCF}$ being is $137.5^{\circ}$ and $128^{\circ}$, respectively, while the $D_{\mathrm{r}}$ stabilized at $6.4 \%$. This points to the most efficient esterification reaction corresponding to the optimum hydrophobic stability of the HMCF.

\subsection{Effect of parameters on graft-copolymerization of cotton fabric by ARGET-ATRP}

To better clarify the relationship between the hydrophobicity of the HMCF and the reaction control parameters, ${ }^{31}$ the graftedcopolymerization parameters of the EACF produced using the ARGET-ATRP process are discussed below.
The grafted-copolymerization of EACF with $50 \mathrm{mg}$ of $\mathrm{Vc}$ and 1-octadecene was performed for $12 \mathrm{~h}$ at $60^{\circ} \mathrm{C}$ to determine the influence of the monomer dosage on the hydrophobic reaction and the hydrophobic properties of the HMCF produced by ARGET-ATRP, as shown in Fig. 7a. The $V_{\mathrm{CA}}$ of the HMCF increases linearly and gradually as the 1-octadecene dosage increases, which is consistent with the characteristics of the ARGET-ATRP mechanism. ${ }^{32}$ Meanwhile, the $V_{\mathrm{RCA}}$ value initially climbs but subsequently decreases by a few degrees, with the optimum $D_{\mathrm{r}}$ value of $5.7 \%$ being attained with a monomer dosage of $2.4 \mathrm{~g}$. These results indicate that a continuous graftedcopolymerization reaction between the esterification cellulose and monomer causes not only a slight increase in the number of grafted sites on the cotton fabric but also contributes to the homopolymerization of the monomer when there is sufficient monomer in the ARGET-ATRP reaction system.

Reductant $\mathrm{Vc}$ is used to reduce the $\mathrm{Cu}(\mathrm{II})$ ions to $\mathrm{Cu}(\mathrm{I})$ ions, attack the halogen atoms in the EACF, and activate any free radicals to maintain the reaction process by the ARGET-ATRP mechanism..$^{33}$ EACF was applied to the grafted copolymerization with $2.4 \mathrm{~g}$ of 1-octadecene and $\mathrm{Vc}$ at $60^{\circ} \mathrm{C}$ for $12 \mathrm{~h}$, to observe the effects of the dosage of reductant $\mathrm{Vc}$ on the hydrophobic modification and hydrophobic properties of the HMCF by the ARGET-ATRP reaction, as shown in Fig. 7b. The results showed that the $V_{\mathrm{CA}}$ of the HMCF generally exhibits a downward trend as the reductant dosage increases, while there is a maximum peak $V_{\mathrm{RCA}}$ at $138^{\circ}$ along with a corresponding minimum $D_{\mathrm{r}}$ value of $5.5 \%$, implying that the
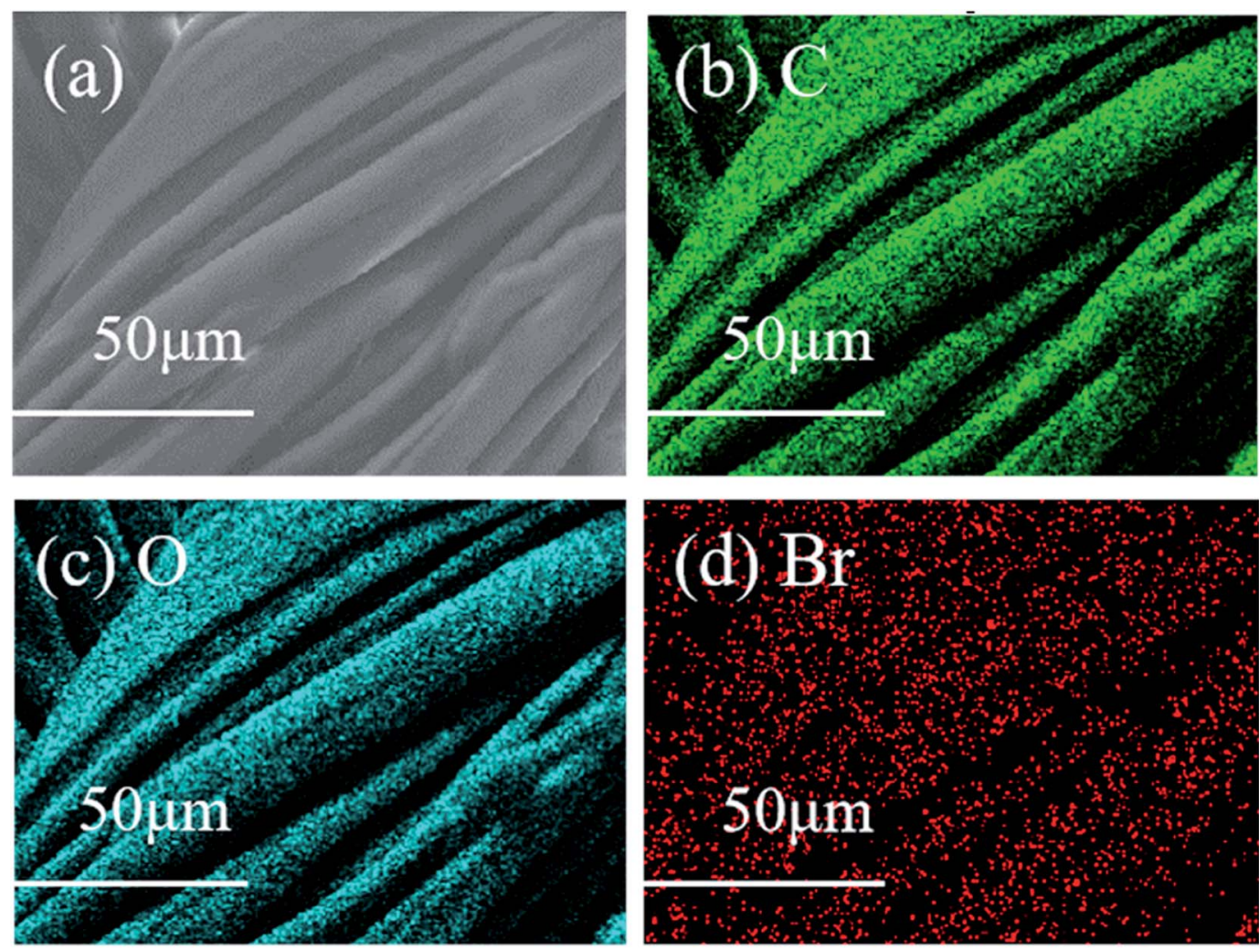

Fig. 6 SEM image of (a) EAFC in $50 \mu \mathrm{m}$ scale, and (b) -(d) corresponding elemental mappings. 

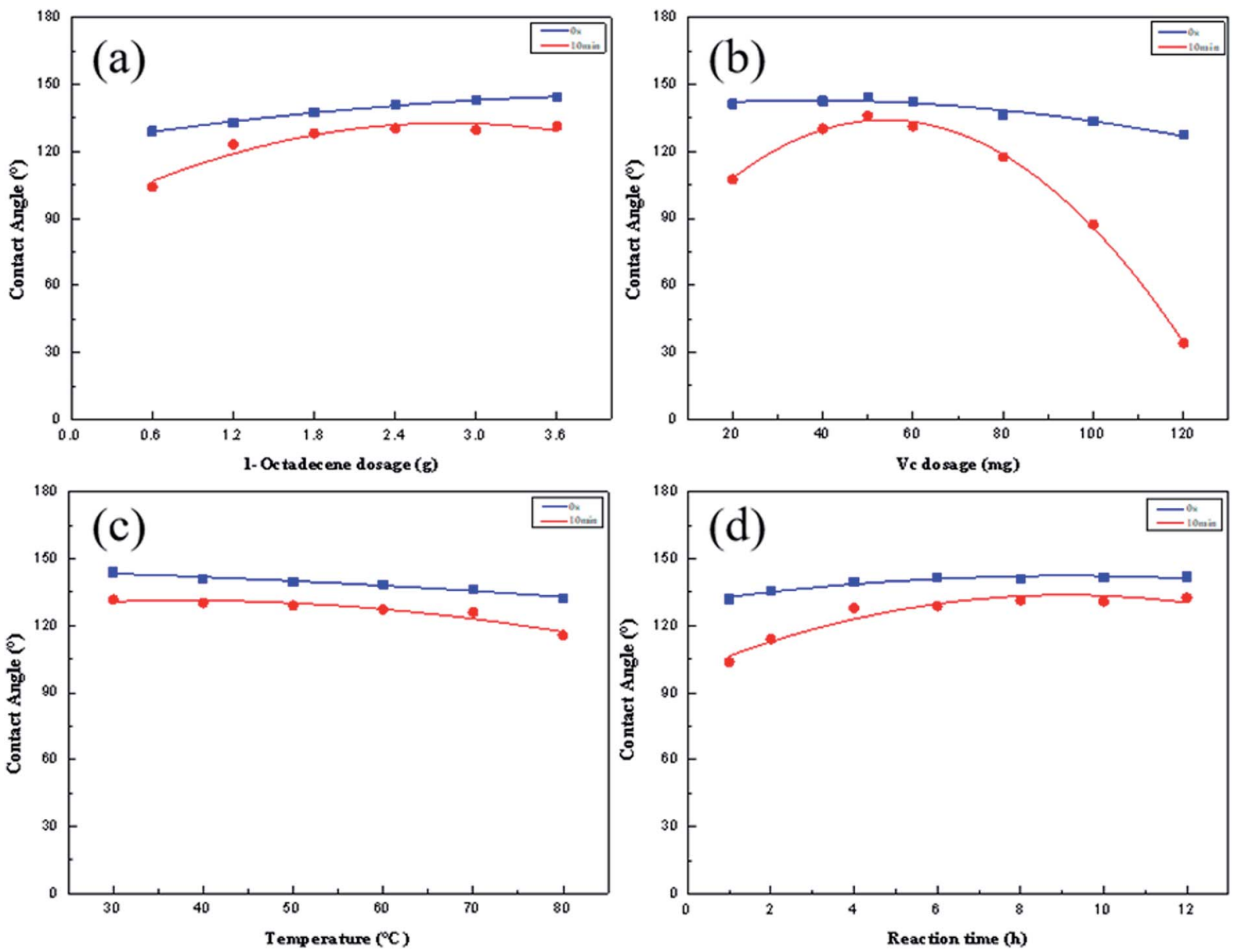

Fig. 7 Variation in CA and RCA of HMCF with (a) 1-octadecene dosage, (b) Vc dosage, (c) reaction temperature, and (d) reaction time.

optimum hydrophobic stability of HMCF is obtained with a $50 \mathrm{mg}$ dosage of $\mathrm{Vc}$. This is because the addition of too much or too little reductant $\mathrm{Vc}$ can convert $\mathrm{Cu}(\mathrm{II})$ ions into $\mathrm{Cu}(\mathrm{I}$ ) ions rapidly and thus stimulate the graft-copolymerization reaction with EACF, while simultaneously promoting the homopolymerization process of the monomers. The synergistic effect between the graft-copolymerization and homopolymerization reaction finally produces a minimum $D_{\mathrm{r}}$ value of $5.5 \%$ at a $50 \mathrm{mg}$ dosage of $\mathrm{Vc}$, implying this to be the best hydrophobic stability of the HMCF. Furthermore, the hydrophobic stability worsens as the Vc dosage is shifted further from the optimum.

A graft-copolymerization reaction between EACF, $50 \mathrm{mg}$ of $\mathrm{Vc}$, and $2.4 \mathrm{~g}$ of 1-octadecene was performed at different temperatures for $12 \mathrm{~h}$ to determine the relationship between $V_{\mathrm{CA}}$ and $V_{\mathrm{RCA}}$ of the HMCF with the reaction temperature, as shown in Fig. 7c. The testing results indicate that the $V_{\mathrm{CA}}$ and $V_{\mathrm{RCA}}$ of the HMCF exhibit a slow synchronous downward trend with an increase in the temperature, while the $D_{\mathrm{r}}$ maintains a relatively stable value of $5.2 \%$ over a reasonable temperature range of $30-45^{\circ} \mathrm{C}$, pointing to the optimal hydrophobic stability for HMCF. This indicates that an excessively high temperature would adversely affect the grafted-copolymerization reaction of the EACF produced using the ARGET-ATRP method.
There are several reasons for the above findings. One is that a higher reaction temperature may adversely affect the stability of the reaction system. For example, the volatilization of small molecules such as solvents and ligands may cause unnecessary damage to the rational composition of the reaction system. Another reason is that the reduced stability of the reductant may retard the process whereby $\mathrm{Cu}(\mathrm{II})$ is converted to $\mathrm{Cu}(\mathrm{I})$ ions. Therefore, if the temperature is too high, the $D_{\mathrm{r}}$ will gradually increase to more than $12 \%$, which seriously affects the hydrophobic stability of the HMCF.

Generally, a longer reaction time is beneficial to the improvement of the hydrophobicity and hydrophobic stability of an HMCF. To determine the relationship between $V_{\mathrm{CA}}$ and $V_{\mathrm{RCA}}$ of the HMCF and the reaction time, a graftcopolymerization reaction of EACF was performed with $2.4 \mathrm{~g}$ of 1-octadecene and $50 \mathrm{mg}$ of $\mathrm{Vc}$ at $35^{\circ} \mathrm{C}$ for a set time, as shown in Fig. $7 \mathrm{~d}$.

The results show that $V_{\mathrm{CA}}$ and $V_{\mathrm{RCA}}$ of HMCF maintain a sustained increase at different levels for the first $8 \mathrm{~h}$, and then tend to stabilize. Correspondingly, the $D_{\mathrm{r}}$ of HMCF gradually decreases to $5.5 \%$ from the initial $20.9 \%$, implying that the hydrophobic stability improves remarkably.

In summary, the ideal conditions for the graft copolymerization reaction of the EACF by ARGET-ATRP were confirmed to 
(a)

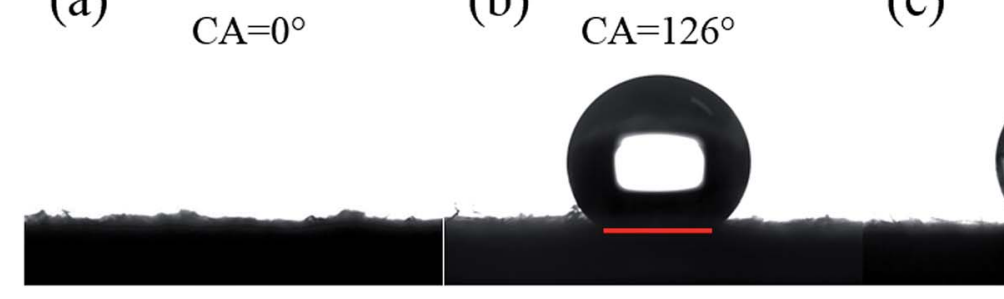

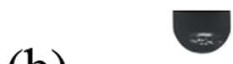

(b) (c)

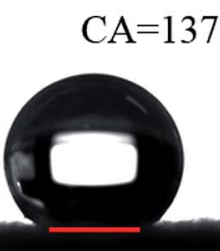

(d)

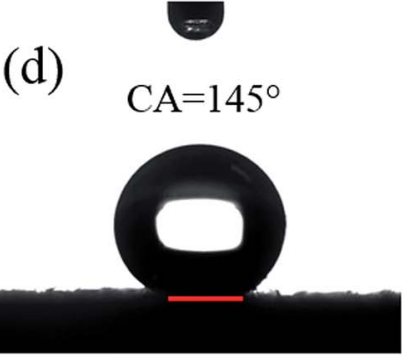

Fig. 8 Hydrophilic cotton fabrics produced by different processes. (a) Raw cotton fabric, (b) HMCF obtained by directly grafted-copolymerization, (c) activated and grafted-copolymerization, and (d) preferred conditions.

be as follows: EACF, $50 \mathrm{mg}$ of $\mathrm{Vc}, 2.4 \mathrm{~g}$ of 1-octadecene, and $17.9 \mathrm{~g}$ of ethanol at a temperature of $30-45^{\circ} \mathrm{C}$ for $8 \mathrm{~h}$.

Given the above findings, we can assume that the optimal reaction conditions will involve the cotton fabric first being treated with $3 \mathrm{wt} \%$ AA to activate it, and then reacted with $0.5 \mathrm{ml}$ of BiB, $0.6 \mathrm{~g}$ of DMAP, $2.5 \mathrm{ml}$ of TEA, and $50 \mathrm{ml}$ of DCM at $30^{\circ} \mathrm{C}$ for $4 \mathrm{~h}$, to obtain the EACF. Finally, the EACF is continuously reacted with $2.4 \mathrm{~g}$ of 1-octadecene, $50 \mathrm{mg}$ of $\mathrm{Vc}, 15 \mathrm{mg}$ of $\mathrm{CuBr}_{2}$, and $52 \mathrm{mg}$ of PMEDTA in $17.9 \mathrm{~g}$ of ethanol at $30-45^{\circ} \mathrm{C}$ for $8 \mathrm{~h}$ to produce the HMCF which has both high hydrophobicity and hydrophobic stability.

\subsection{Comparison of hydrophobicity of raw cotton fabric and HMCFs produced by different reaction processes}

Fig. 8 shows hydrophilic cotton fabric samples produced by different processes. The raw cotton fabric is shown in Fig. 8a. This is more hydrophilic than hydrophobic due to the nature of the cellulose. ${ }^{34}$ The corresponding $V_{\mathrm{CA}}$ is 0 . In contrast with Fig. 8a, the HMCF that is produced by a directly grafted copolymerization process of raw cotton fabric by the ARGET-ATRP mechanism, gives a $V_{\mathrm{CA}}$ of $126^{\circ}$ and a $D_{\mathrm{r}}$ of $19.8 \%$ (Fig. $8 \mathrm{~b}$ ). Furthermore, the HMCF produced by a successively activated and grafted copolymerization process, applied to the raw cotton fabric by the ARGET-ATRP mechanism, exhibits a $V_{\mathrm{CA}}$ of $137^{\circ}$ and a $D_{\mathrm{r}}$ of $6.9 \%$ (Fig. 8c). Finally, as shown in Fig. 8d, the $V_{\mathrm{CA}}$ of the HMCF prepared under the preferred conditions described in this paper increases to $145^{\circ}$, and the corresponding $D_{\mathrm{r}}$ decreases to $5.5 \%$. This indicates that the activation of the raw cotton fabric, together with the optimal modified reaction under the ARGET-ATRP conditions, can significantly improve the hydrophobicity and hydrophobic stability of the HMCF.

\subsection{Surface structure and morphology of cotton fabric subjected to graft-copolymerization process}

The microscopic morphological changes in the raw cotton fabric, along with its hydrophobic modification process, are shown in Fig. 9. Low-magnification micrographs of the raw cotton fabric, activated cotton fabric, EACF, and HMCF are shown in Fig. 9a-d. It is difficult to differentiate between the treatment processes applied to the cotton fabric, regardless of their knitting density, mesh size, and physical appearance. Therefore, the flux and permeability of the cotton fabric itself are not greatly affected..$^{35}$ Fig. $9 \mathrm{e}-\mathrm{h}$ show the raw cotton fabric, activated cotton fabric, EACF, and HMCF, respectively, at high magnifications. In Fig. 9e, the fiber surface of the raw cotton fabric is relatively smooth. In Fig. 9f, the fiber surface of the
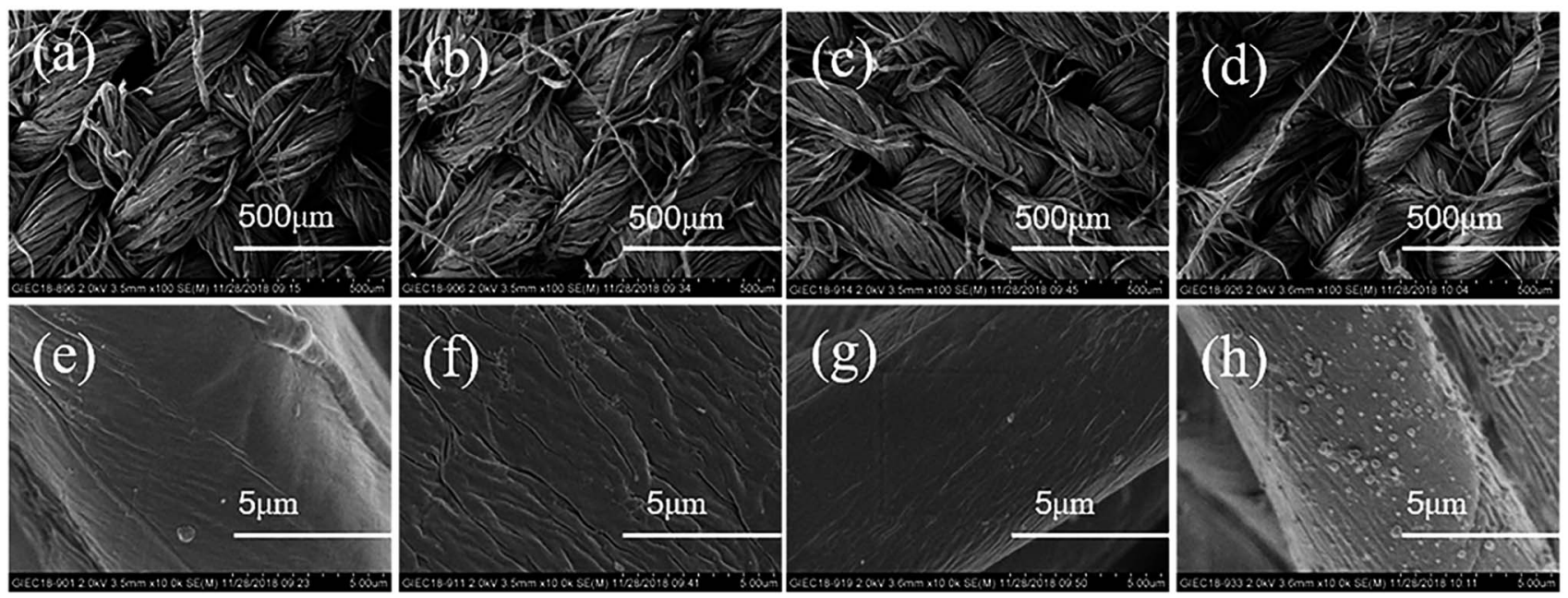

Fig. 9 (a and e) SEM images (of different magnifications) of raw cotton fabric, (b and f) activated cotton fabric, (c and g) EACF, and (d and h) HMCF. 

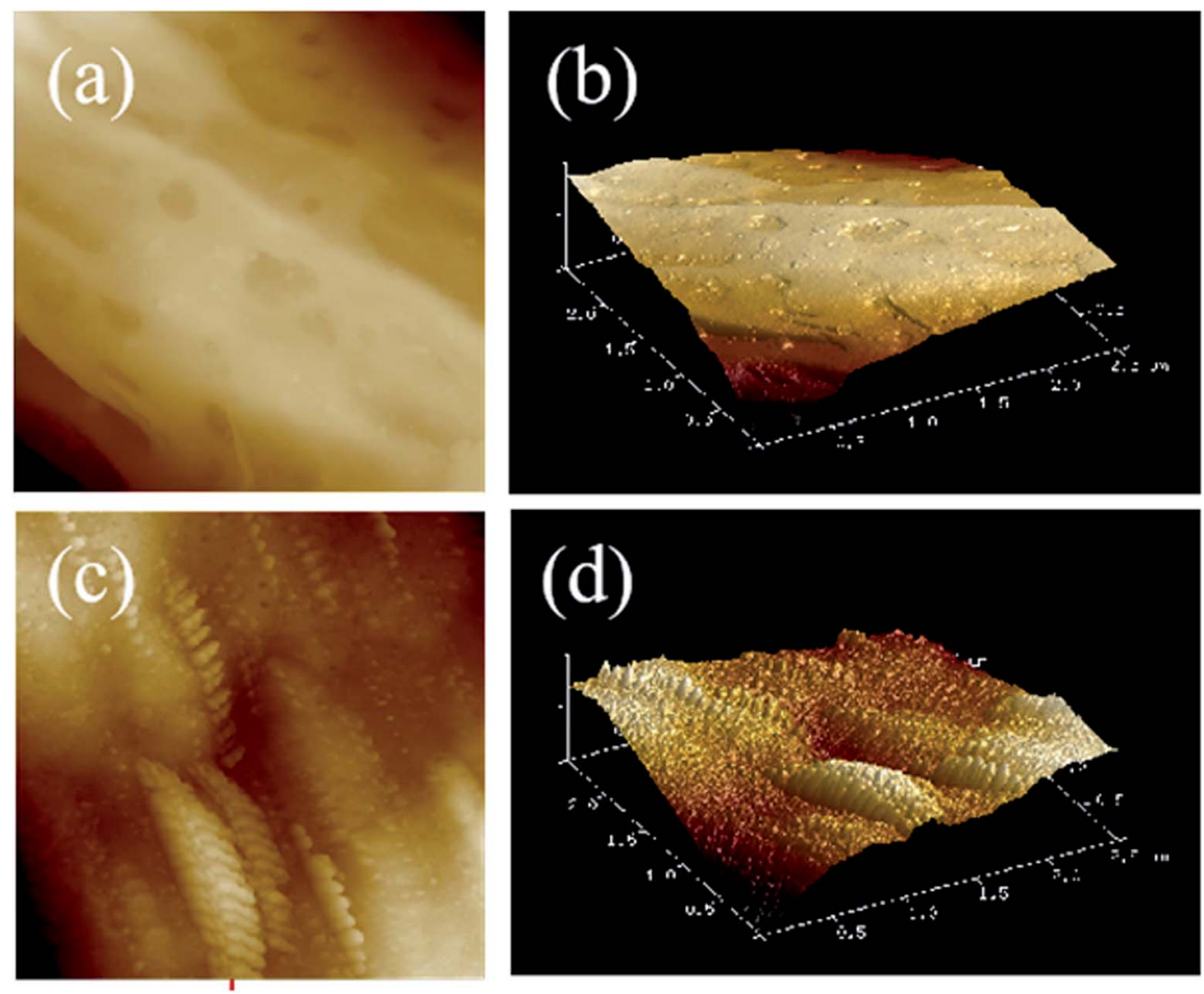

Fig. 10 AFM images with different dimensions of ( $a$ and b) raw cotton fiber and (c and d) HMCF.

activated cotton fabric exhibits highly irregular wrinkles and a greater surface roughness, which is helpful for releasing more of the surface hydroxyl groups of the cellulose. In Fig. 9g, the fiber surface of the EACF is characterized by fine irregular and rough folds. In Fig. $9 \mathrm{~h}$, there are more particles with a diameter of $50-300 \mathrm{~nm}$ on the surface of the HMCF fibers, which may be particles of the 1-octadecene grafted cellulose. The micro/nanosize structure forms the structural basis for transforming the extreme hydrophilicity of the cotton fabric into stable superhydrophobicity.

In addition, AFM micrographs of the fiber surfaces of the raw cotton fabric and the HMCF, corresponding to before and after
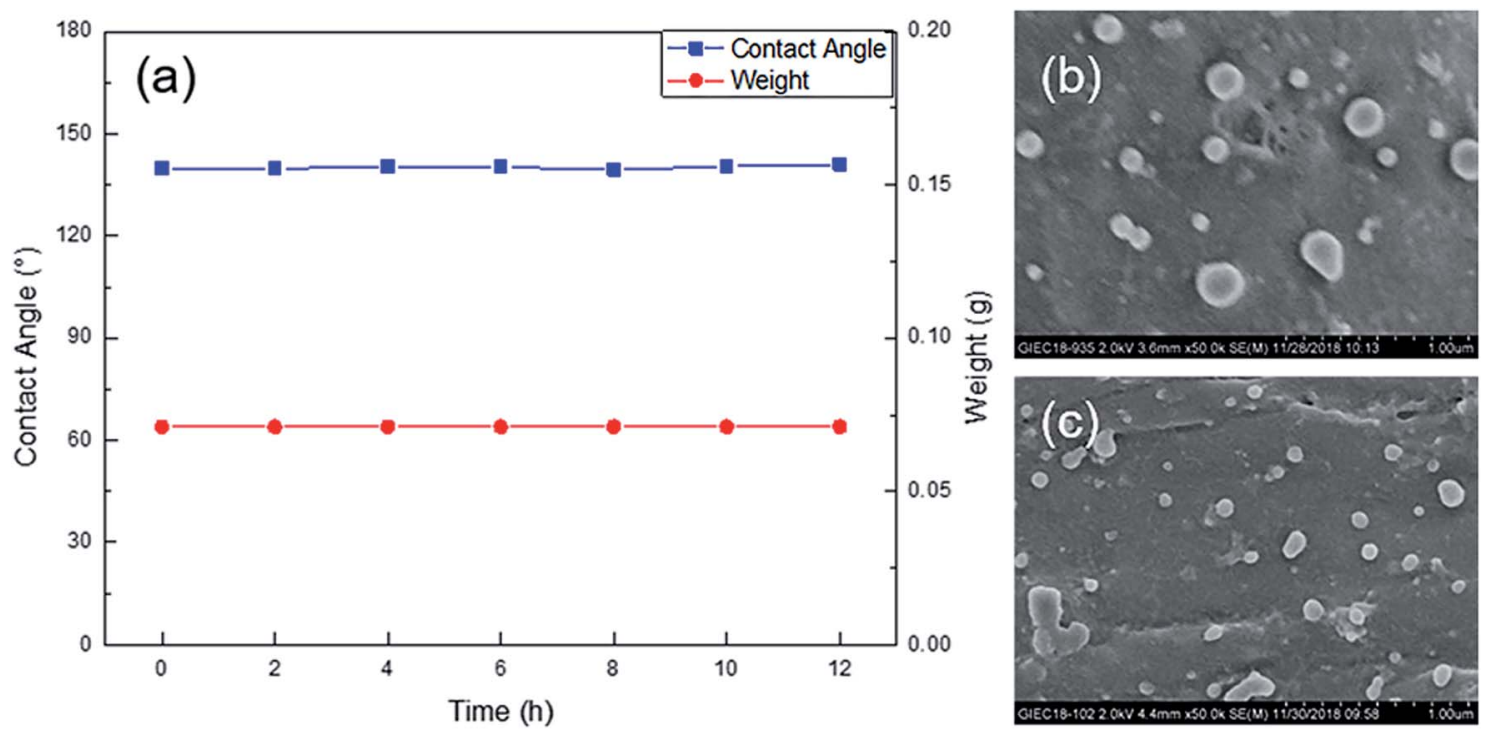

Fig. 11 HMCF mass and contact angle change after Soxhlet extraction (a), and SEM images before (b) and after (c) Soxhlet extraction. 
the hydrophobic modification, are shown in Fig. 10. The fiber surface of the raw cotton fabric is relatively smooth, and the root mean square roughness $R_{\mathrm{q}}$ is $37.9 \mathrm{~nm}$. In contrast, the fiber surface of the HMCF is very rough, and the root mean square roughness $R_{\mathrm{q}}$ is $97 \mathrm{~nm}$, as shown in Fig. 10c and d. This rough surface of the cotton fabric is mainly caused by the synergistic effect between a large number of wrinkles generated by the activation treatment and non-polar polymer microsphere particles produced by the grafting copolymerization process.

In short, the activation process promotes the ARGET-ATRP graft copolymerization reaction and contributes to the superhydrophobicity and hydrophobic stability of the cotton fabric.

\subsection{Stability test of graft copolymer coating on cotton fiber surface}

The stability and durability of the cotton fiber surface coating determine the practical application properties of the material. ${ }^{36-38}$ The HMCF was subjected to Soxhlet extraction in a mixed solvent for $12 \mathrm{~h}$. Then, every $2 \mathrm{~h}$, it was taken out and dried, and its mass and contact angle change were measured. The mass and contact angle change of the HMCF are shown in Fig. 11a. After $12 \mathrm{~h}$ of Soxhlet extraction, its mass does not change, and the contact angle fluctuates within $1^{\circ}$ owing to measurement error. In addition, we also recorded SEM images of the HMCF after Soxhlet extraction. As shown in Fig. 11b and c, the graft density, shape, and size of the polymer microspheres on the surface of the cotton fiber after the Soxhlet extraction remained almost the same. Therefore, we can confirm that the polymer coating constructed by graft copolymerization is very stable and durable, and it is difficult to physically peel it off.

\section{Conclusion}

The ARGET-ATRP process is an effective means of preparing a hydrophobically modified cotton-fabric filter, a type of advanced functional filter material, for use in high-efficiency and high-flux oil-water separation.

In the present study, an activation treatment was applied to the raw cotton fabric to improve and strengthen the hydrophobically grafted modification reaction with 1-octadecene through the application of the ARGET-ATRP mechanism.

The activation treatment with $3 \mathrm{wt} \%$ AA significantly promotes the esterification reaction of the cotton fabric. Then, the subsequent graft copolymerization reaction of the activated cotton fabric by ARGET-ATRP was achieved under the preferred reaction conditions of $0.5 \mathrm{ml}$ of $\mathrm{BiB}, 0.6 \mathrm{~g}$ of DMAP, $2.5 \mathrm{ml}$ of TEA, and $50 \mathrm{ml}$ of DCM at $30{ }^{\circ} \mathrm{C}$ for $4 \mathrm{~h}$ to obtain an EACF. Furthermore, the EACF was continuously reacted with $2.4 \mathrm{~g}$ of 1octadecene, $50 \mathrm{mg}$ of $\mathrm{Vc}, 15 \mathrm{mg}$ of $\mathrm{CuBr}_{2}, 52 \mathrm{mg}$ of PMEDTA, and $17.9 \mathrm{~g}$ of ethanol at $35^{\circ} \mathrm{C}$ for $8 \mathrm{~h}$ to obtain the HMCF.

Finally, the optimal $V_{\mathrm{CA}}$ of the HMCF was found to be $145^{\circ}$, and the corresponding contact angle decay rate $D_{\mathrm{r}}$ was stable at about $5.5 \%$, implying high levels of both hydrophobicity and hydrophobic stability. The microscopic morphology of the HMCF reflects the micro-/nano-level particle structure of the super-hydrophobic cotton fiber surface.

\section{Conflicts of interest}

There are no conflicts to declare.

\section{References}

1 P. Kajitvichyanukul, Y. T. Hung and L. K. Wang, Handb. Environ. Eng., 2006, 30, 7-8.

2 M. A. Shannon, P. W. Bohn and M. Elimelech, Nature, 2008, 452, 301-310.

3 M. Padaki, R. S. Murali and M. Abdullah, Desalination, 2015, 357, 197-207.

4 J. F. Liu, X. Y. Xiao and Y. L. Shi, Appl. Surf. Sci., 2014, 297, 33-39.

5 X. Zhang, T. Geng and Y. G. Guo, Chem. Eng. J., 2013, 231, 414-419.

6 Q. M. Pan, M. Wang and H. B. Wang, Appl. Surf. Sci., 2008, 254, 6002-6006.

7 D. Roy, M. Semsarilar, J. T. Guthrie and S. Perrier, Chem. Soc. Rev., 2009, 38, 2046-2064.

8 Y. X. Wang and L. N. Zhang, Chin. Sci. Bull., 2008, 34, 66-76. 9 K. Y. Law, Pure Appl. Chem., 2015, 87, 759-765.

10 M. S. Selim, H. Yang and F. Q. Wang, Appl. Surf. Sci., 2019, 466, 40-50.

11 I. S. Bayer, A. Steele and P. J. Martorana, Appl. Phys. Lett., 2009, 94, 163902.

12 X. Y. Zhou, Z. Z. Zhang and X. H. Xu, ACS Appl. Mater. Interfaces, 2013, 5, 7208-7214.

13 J. X. Wu and J. Y. Li, Sci. Rep., 2013, 3, 1-6.

14 Y. Q. Qing, Y. S. Zheng and C. B. Hu, Appl. Surf. Sci., 2013, 285, 583-587.

15 C. Y. Cao, M. Z. Ge and J. Y. Huang, J. Mater. Chem. A, 2016, 4, 12179-12187.

16 X. D. Chen, Y. F. Chen and T. Jin, J. Mater. Sci., 2018, 53, 11253-11264.

17 Y. J. Yao and H. R. Wang, Mater. Rev., 2018, 32, 3478-3488.

18 D. Y. Ye, H. Huang and H. Q. Fu, Chin. J. Chem. Eng., 2006, 57, 1782-1791.

19 A. Carlmark and E. Malmstrom, J. Am. Chem. Soc., 2002, 124, 900-901.

20 J. S. Wang and K. Matyjaszewski, J. Am. Chem. Soc., 1995, 117, 5614-5615.

21 Q. Lou and D. A. Shipp, ChemPhysChem, 2012, 13, 32573261.

22 G. Morandi, L. Heath and W. Thielemans, Langmuir, 2009, 25, 8280-8286.

23 X. F. Sui, J. Y. Yuan and M. Zhou, Biomacromolecules, 2008, 9, 2615-2620.

24 P. Vlcek, M. Janata and P. Latalova, Polymer, 2006, 47, 25872595.

25 W. Jakubowski, K. Min and K. Matyjaszewski, Macromolecules, 2006, 39, 39-45.

26 S. Hansson, E. Ostmark and A. Carlmark, ACS Appl. Mater. Interfaces, 2009, 1, 2651-2659.

27 K. K. Ou, X. J. Wu and B. X. Wang, Cellulose, 2017, 24, 52115224.

28 J. Cai and L. N. Zhang, Macromol. Biosci., 2005, 5, 539-548. 
29 A. Carlmark and E. Malmstrom, Biomacromolecules, 2003, 4, 1740-1745.

30 N. Chan, M. F. Cunningham and R. A. Hutchinson, Macromol. Chem. Phys., 2010, 209, 1949.

31 R. N. Foster, P. K. Johansson and N. R. Tom, J. Vac. Sci. Technol., A, 2015, 33, 05E131.

32 I. D. Grishin, S. A. Stakhi, D. Y. Kurochkina and D. F. Grishin, J. Polym. Res., 2018, 25, 261.

33 W. Jakubowski, B. Kirci-Denizli, R. R. Gil and K. Matyjaszewski, Macromol. Chem. Phys., 2008, 209, 32-39.
34 D. Klemm and B. Heublein, Angew. Chem., Int. Ed., 2005, 44, 3358-3393.

35 J. X. Wu and J. Y. Li, RSC Adv., 2015, 5, 27752-27758.

36 B. Deng, R. Cai and J. Y. Li, Adv. Mater., 2010, 48, 5473-5477.

37 M. Yu, Z. Q. Wang and J. Y. Li, ACS Appl. Mater. Interfaces, 2013, 5, 3697-3703.

38 M. Yu, Z. Q. Wang and J. Y. Li, ACS Appl. Mater. Interfaces, 2016, 8, 19866-19871. 